Pesq. Vet. Bras. 36(10):1009-1013, outubro 2016 DOI: $10.1590 / \mathrm{S} 0100-736 \mathrm{X} 2016001000015$

\title{
Análise histoquímica das glândulas anexas do aparelho reprodutor do macho de paca (Cuniculus paca) ${ }^{1}$
}

\begin{abstract}
Aretuza C. Capalbo², Claudinei Cruz ${ }^{3}$, Fabrício S. de Oliveira² , Tais H.C. Sasahara², Leonardo M. Leal ${ }^{4}$, Luciana S. Simões ${ }^{5}$, Maria A. Miglino ${ }^{5}$ e Márcia R.F. Machado ${ }^{2 *}$

ABSTRACT.- Capalbo A.C., Cruz C., De Oliveira F.S., Sasahara T.H.C., Leal L.M., Simões L.S., Miglino M.A. \& Machado M.R.F. 2016. [Histochemical analysis of the accessory glands of male paca (Cuniculus paca).] Análise histoquímica das glândulas anexas do aparelho reprodutor do macho de paca (Cuniculus paca). Pesquisa Veterinária Brasileira 36(10):10091013. Departamento de Morfologia e Fisiologia Animal, Faculdade de Ciências Agrárias e Veterinárias, Universidade Estadual Paulista, Via de Acesso Prof. Paulo Donato Castellane s/n, Jaboticabal, SP 14884-900, Brazil. E-mail: marcia.machado@gmail.com

Paca is a wild rodent typical of the tropical region. In order to study this species with focus on the proper management and preservation, this study aims to characterize the histochemistry of the accessory glands of the reproductive tract of the male paca. For this purpose, histological sections were stained with Periodic Acid-Schiff (PAS), Alcian Blue $(\mathrm{AB}), \mathrm{PAS}+\mathrm{AB}$ e PAS + Amilase. In the histochemical reaction of the bulbouretral gland was found that the epithelium produces secretion rich in neutral and acid glycoproteins, glycosaminoglycans, and in some regions produces more than one type of secretion. The epithelium did not contain any glycogen. In the vesicular gland the epithelium had bush border stained by neutral glycoproteins, but no acid glycoproteins, glycogen or glycosaminoglycan. The coagulating gland showed small amount of neutral glycoproteins in the brush border of the epithelium, without glycogen. It is concludes that the accessory glands of paca have histochemical characteristics that share some similarity with other species of the Order Rodentia, with some glands with neutral and acid glycoproteins, mainly in the epithelium of the bulbouretral gland and in the brush border of the other glands.
\end{abstract}

INDEX TERMS: Cuniculus paca, male paca, histochemistry, accessory glands, Alcian blue, hystricomorph, Periodic Acid-Schiff, rodent, reproduction system.

RESUMO.- A paca (Cuniculus paca) é um roedor típico de regiões tropicais. Com a finalidade de estudar esta espécie selvagem para manejo adequado e sua preservação, objetivou-se neste trabalho caracterizar a histoquímica das

\footnotetext{
${ }^{1}$ Recebido em 12 de março de 2015.

Aceito ara publicação em 6 de maio de 2016.

${ }^{2}$ Departamento de Morfologia e Fisiologia Animal, Faculdade de Ciências Agrárias e Veterinárias (FCAV), Universidade Estadual Paulista (Unesp), Via de Acesso Prof. Paulo Donato Castellane s/n, Jaboticabal, SP 14884-900, Brasil.

${ }^{3}$ Centro Universitário da Fundação Educacional de Barretos (Unifeb), Av. Professor Roberto Frade Monte 389, Bairro Aeroporto, Barretos, SP 14783-226, Brasil.

${ }^{4}$ Departamento de Medicina Veterinária, Faculdade Ingá (Uningá), Rodovia PR-317 no.6114, Parque Industrial Duzentos, Maringá, PR 87035510, Brasil.

${ }^{5}$ Departamento de Cirurgia, Faculdade de Medicina Veterinária e Zootecnia (FMVZ), Universidade de São Paulo (USP), Av. Prof. Orlando Marques de Paiva 87, Cidade Universitária, São Paulo, SP 05508-010, Brasil.
}

glândulas anexas do trato reprodutor do macho da paca. Para este fim, cortes histológicos dessas glândulas foram submetidas às reações histoquímicas com Ácido Periódico de Schiff (PAS), Alcian blue (AB), PAS. + AB. e PAS + Amilase. Na glândula bulbouretral foi constatado que o epitélio produz secreção rica em glicoproteínas neutras e ácidas, glicosaminoglicanas, e em algumas regiões produz mais de um tipo de secreção. Não foi observada a presença de glicogênio no epitélio. Na glândula vesicular, seu epitélio em borda em escova corou-se por glicoproteínas neutras e também por substância de composição desconhecida, não contendo glicoproteínas ácidas, glicogênio ou glicosaminoglicanas. Verificou-se presença de pequena quantidade de glicoproteínas ácidas e neutras na próstata, em especial na mucosa, além de glicoproteínas ácidas carboxiladas e sulfatadas em pequena quantidade no tecido conjuntivo da lâmina própria dessa glândula. Por fim, a glândula coaguladora apresentou pequena quantidade de glicoproteínas 
neutras na borda em escova de seu epitélio e substância de composição desconhecida, sendo ausente o glicogênio. Conclui-se que as glândulas anexas do trato reprodutor da paca apresentam características histoquímicas que compartilham certa similaridade com outras espécies da ordem Rodentia, com a presença de glicoproteínas neutras e ácidas em algumas glândulas, principalmente no epitélio da glândula bulbouretal e na borda em escova do epitélio das demais glândulas.

TERMOS DE INDEXAÇÃO: Cuniculus paca, paca macho, histoquímica, glândulas accessóririas, Ácido periódico de Schiff, Alcian blue, histricomorfo, roedor, sistema reprodutor.

\section{INTRODUÇÃO}

Os roedores são animais amplamente utilizados em estudos experimentais biomédicos, genéticos e principalmente reprodutivos (Vásquez \& Del Sol 2010). Assim, estudos sobre as características morfológicas das glândulas anexas do trato reprodutor masculino de roedores são amplos na literatura (Cooper \& Schiller 1975, Toma \& Buzzell 1988, Mollineau et al. 2009, Chaves et al. 2010, Menezes et al. 2010, Rodrigues et al. 2013). Na paca as glândulas anexas do trato reprodutor masculino compõem-se dos seguintes pares glandulares: vesicular, coaguladora, próstata e bulbouretral (Borges et al. 2014). 0 ejaculado é constituído, não só dos espermatozóides, mas em sua maior parte, pelo fluído produzido nas glândulas acessórias masculinas; este material atua no transporte e nutrição dos espermatozóides, age também no trato genital feminino, neutralizando o excesso de acidez deste local (Hafez \& Hafez 2004).

0 conhecimento gerado a partir deste estudo, inerente ao detalhamento das características das estruturas do sistema reprodutor da paca, certamente poderá ser aplicado no planejamento e estruturação dos mecanismos de preservação dessa espécie, estabelecendo padrões de referência de sua biologia reprodutiva. Assim, objetivou-se na presente pesquisa caracterizar microscopicamente as glândulas anexas do trato reprodutor do macho da paca adulta (glândulas bul- bouretral, coaguladora, vesicular e próstata), com ênfase às células epiteliais, mediante a análise histoquímica destas estruturas, para a análise da intensidade e das características das glicoproteínas neutras e ácidas (sulfatadas e carboxiladas) e do glicogênio, caso estejam presentes nessas células.

\section{MATERIAL E MÉTODOS}

Para a realização desta pesquisa foram usadas quatro pacas (Cuniculus paca) machos adultos cuja metodologia foi aprovada pelo Comitê de Ética no Uso de Animais (CEUA) da Faculdade de Ciências Agrárias e Veterinárias (FCAV-Unesp), Jaboticabal-SP, de acordo com o Colégio Brasileiro de Experimentação Animal (Cobea) sob o número de protocolo 017754/13.

Os animais pertenciam ao Setor de Animais Silvestres do Departamento de Zootecnia da Faculdade de Ciências Agrárias e Veterinárias da Unesp-Jaboticabal. A eutanásia foi realizada mediante sedação prévia com meperidina $(3 \mathrm{mg} / \mathrm{kg})$ associada a midazolan $(1 \mathrm{mg} / \mathrm{kg})$ pela via intramuscular, anestesia geral com quetamina $(25 \mathrm{mg} / \mathrm{kg})$ e xilazina $(0,5 \mathrm{mg} / \mathrm{kg})$ também pela via intramuscular, e por fim injeção intracardíaca de cloreto de potássio 19,1\%, dose-efeito, até a parada cardiorrespiratória (Leal et al. 2014)

Para a descrição histoquímica das glândulas acessórias do trato genital masculino da paca, fragmentos desses órgão foram fixados em solução de formol 10\% tamponado, por 24 horas. Após a fixação, estes fragmentos foram processados de acordo com as técnicas de rotina histológica (Tolosa et al. 2003). Estes cortes foram submetidos às seguintes reações histoquímicas: PAS (Ácido Periódico de Schiff), Alcian blue (AB) pH 0,5 e pH 2,5 para a diferenciação das mucinas neutras (glicogênio) e ácidas (muco substâncias sulfatadas e carboxiladas) (Behmer et al. 1976), PAS + A.B. e PAS + Amilase. Finalmente, a fotodocumentação foi realizada em fotomicroscópio Olympus BX-50 com a utilização de filme Fuji film Fujicolor ASA100.

\section{RESULTADOS}

Os resultados das reações histoquímicas nos tecidos das glândulas genitais acessórias do macho de paca para Ácido Periódico de Schiff (PAS), Alcian Blue (AB), Ácido Periódico de Schiff e Alcian Blue (PAS+AB) e Ácido Periódico de Schiff e Amilase (PAS+Amilase) estão descritos no Quadro 1 e

Quadro 1. Reações histoquímicas das glândulas anexas do trato reprodutor masculino na paca

\begin{tabular}{|c|c|c|c|c|}
\hline & PAS & $\mathrm{AB}$ & $\mathrm{PAS}+\mathrm{AB}$ & PAS + Amilase \\
\hline \multicolumn{5}{|l|}{ Glândula bulbouretral } \\
\hline Tecido conjuntivo & + & - & - & - \\
\hline Camada muscular & + & - & - & - \\
\hline Epitélio glandular & +++ & ++ & ++ & +++ \\
\hline \multicolumn{5}{|l|}{ Glândula vesicular } \\
\hline Tecido conjuntivo & + & - & - & + \\
\hline Camada muscular & + & - & - & + \\
\hline Epitélio glandular & $\begin{array}{c}- \\
\text { (borda em escova }+ \text { ) }\end{array}$ & - & + & $\stackrel{+}{(\text { borda em escova }++)}$ \\
\hline \multicolumn{5}{|l|}{ Próstata } \\
\hline Tecido conjuntivo & ++ & + & - & ++ \\
\hline Camada muscular & - & - & - & - \\
\hline $\begin{array}{l}\text { Epitélio glandular } \\
\text { Glândula coaguladora }\end{array}$ & (borda em escova ++ ) & - & (borda em escova + ) & +++ \\
\hline Tecido conjuntivo & - & + & - & +++ \\
\hline Camada muscular & - & - & - & + \\
\hline Epitélio glandular & (borda em escova +) & - & (borda em escova + ) & $\begin{array}{c}++ \\
\text { (borda em escova+) }\end{array}$ \\
\hline
\end{tabular}

Intensidade da reação: + fraco, ++ moderado, +++ intenso, - Reação negativa. 
podem ser observados nas Figuras 1, 2, 3, 4 e 5. 0 Quadro 1 mostra ainda que, apesar de algumas glândulas apresentarem reações negativa, em alguns casos, a região luminal do epitélio, denominada de borda em escova, mostrou-se corada com intensidade diferente, dependendo da glândula.

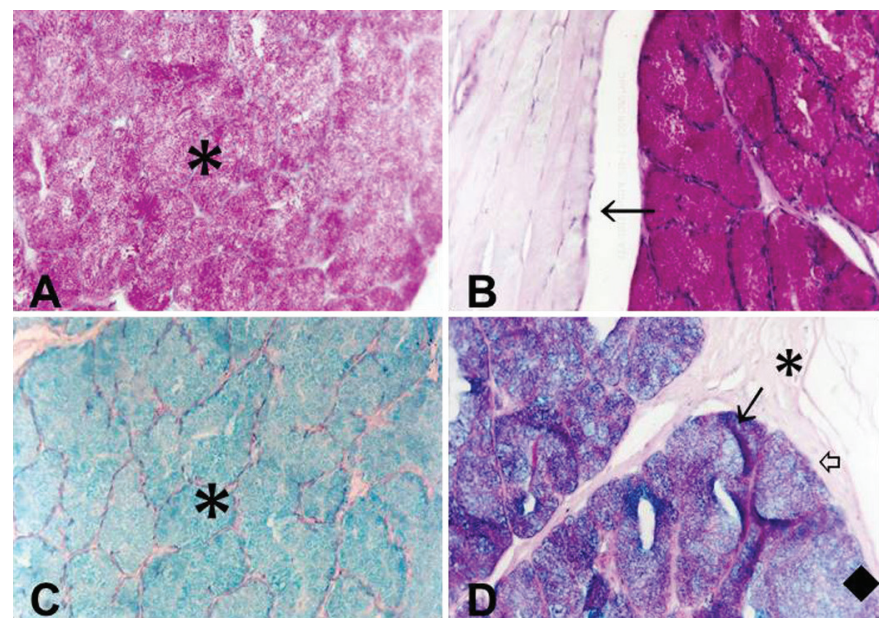

Fig.1. (A) Glândula bulbouretral de paca. Os ácinos coram-se em rosa forte (asterisco) na reação de PAS, obj.20x. (B) Na reação PAS+amilase, os ácinos se coram em rosa forte pelo PAS (asterisco), indicando a presença de glicoproteínas neutras e ausência de glicogênio nas células, e a camada muscular externa não reage (seta). Obj.20x. (C) Porção secretora da glândula corada em azul celeste pela reação de $\mathrm{AB}$ pH 2,5 (asterisco). Obj.20x. (D) Reação PAS+AB, mostrando que a região dos ácinos se cora em rosa (seta vazada), azul (losango) e roxo (seta), mas a camada muscular externa não reage (asterisco). Obj.20x.

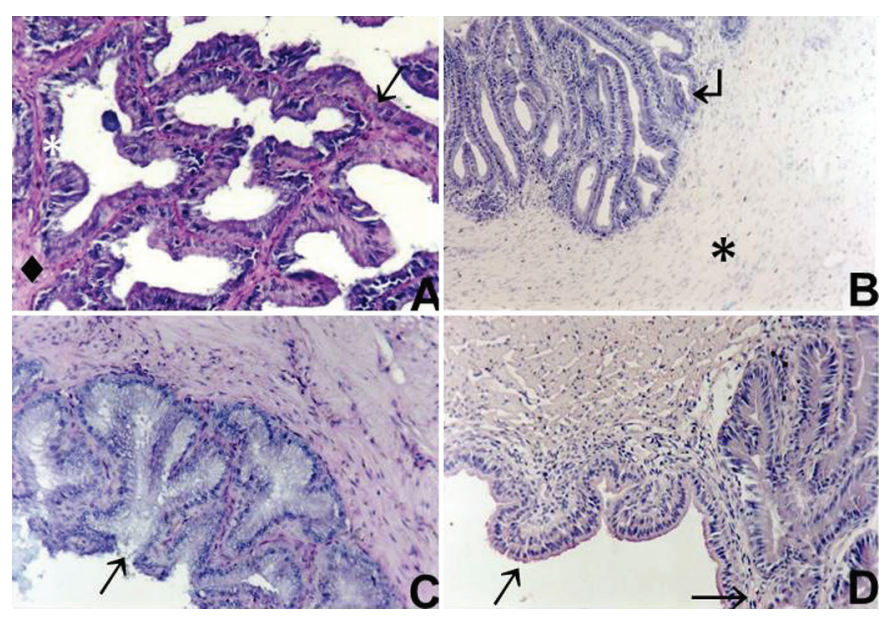

Fig.2. (A) Glândula vesicular da paca; a camada muscular (losango) mostrou-se pouco reativa ao PAS, mas na lâmina própria (asterisco) e na borda em escova das células epiteliais (cabeça de seta) foi possível observar a coloração rosa forte. Obj.20x. (B) Na coloração com $\mathrm{AB}$ não houve reação nos tecidos muscular (asterisco), conjuntivo ou epitelial (seta). Obj.10x. (C) Na reação $\mathrm{PAS}+\mathrm{AB}$ houve reação positiva fraca do epitélio, que se corou em roxo claro (seta), mostrando que as células possuem no seu citoplasma substâncias com afinidade por esse conjugado. Obj.20x. (D) Na reação PAS+ amilase a reação foi positiva em todas as camadas, sendo mais acentuada na borda em escova do epitélio glandular (setas). Obj.20x.

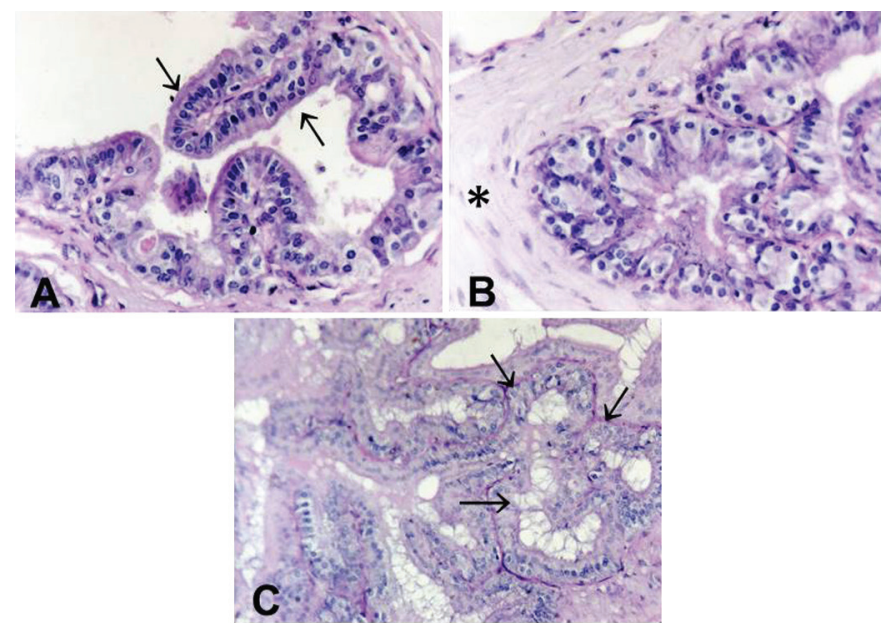

Fig.3. (A) Próstata da paca; a reação ao PAS foi positiva no tecido conjuntivo da lâmina própria (asterisco) e na borda em escova das células epiteliais (seta). Obj.40x. (B) Nos septos a reação ao PAS foi negativa (asterisco). Obj.40x. (C) Aspecto panorâmico da região da mucosa, onde é possível observar a lâmina própria corada em rosa mais evidente (setas). PAS, obj.20x.

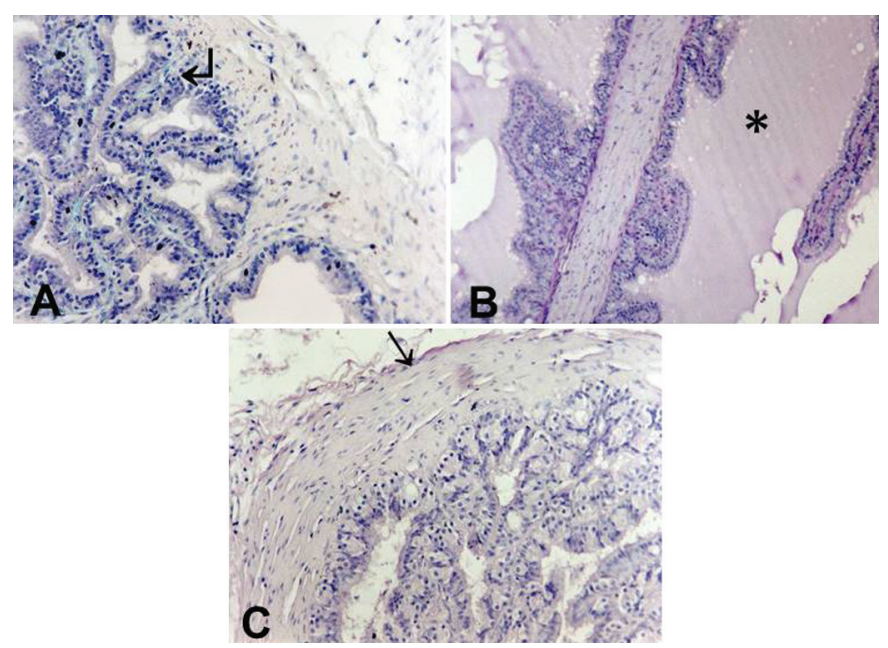

Fig.4. (A) Próstata da paca; na coloração AB pH 2,5 observa-se que o resultado é positivo fraco na lâmina própria, que se cora em azul (seta). Obj.20x. (B) Na reação PAS+AB a borda em escova das células epiteliais apresentou resultado positivo. As demais camadas não reagiram; na luz da glândula é possível observar o produto de secreção corado em rosa (asterisco). Obj.10x. (C) Na coloração PAS+amilase a reação foi positivo forte no epitélio (cabeça de seta), positivo médio no tecido conjuntivo da lâmina própria e cápsula (seta) e negativo no tecido muscular. Obj.20x.

\section{DISCUSSÃO}

No presente experimento comprovou-se que a glândula bulbouretral da paca, por reagir fortemente ao P.A.S. no epitélio glandular, secreta glicoproteínas neutras que não o glicogênio, pois na reação PAS+ amilase o epitélio corou-se fortemente. A reação positiva para $A B$ no epitélio da glândula significa que também há glicoproteínas ácidas ou glicosaminoglicanas na secreção. 0 epitélio também foi reativo para $\mathrm{PAS}+\mathrm{AB}$ indicando que há reação à substância formada pelo conjugado dessas duas colorações. Em outro 


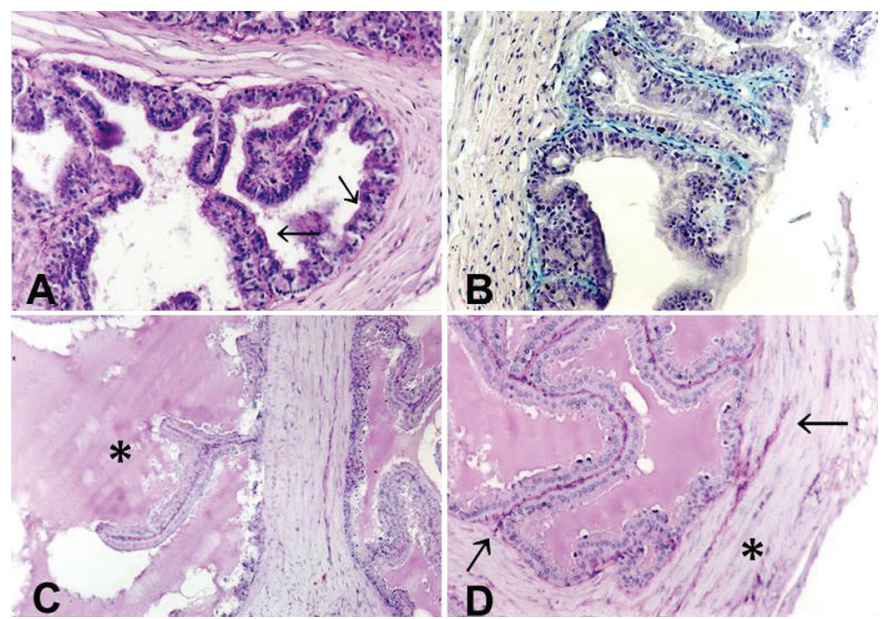

Fig.5. (A) Glândula coaguladora da paca; na reação ao PAS a borda em escova do epitélio (setas) e a lâmina própria reagiram com baixa intensidade. Obj.20x. (B) Na coloração AB pH 2,5 apenas o tecido conjuntivo da lâmina própria reagiu (cor azulada). Obj.20x. (C) Na reação de PAS+AB apenas a borda das células epiteliais reagiu com baixa intensidade. Nota-se na figura o produto de secreção na luz da glândula (asterisco). Obj.10x. (D) Na coloração PAS+amilase é possível observar que o tecido conjuntivo reage fortemente (setas), enquanto o epitélio reage de forma positiva, porém com menor intensidade. A camada muscular apresenta reação positivo fraco (asterisco). Obj.20x.

roedor, a viscacha (Lagostomus maximus maximus) esta glândula não apresentou reatividade para PAS e AB (Chaves et al. 2010).

A histoquímica da glândula vesicular do coelho (Oryctolagus Cuniculus), da cobaia (Cavia porcellus) e da viscacha revelou negatividade para PAS (Del Sol \& Vásquez 2002, Chaves et al. 2010, Vásquez \& Del Sol 2010), semelhante ao descrito nesse trabalho na paca onde os tecidos, muscular e conjuntivo, coraram-se fracamente por PAS e o epitélio apresentou reação negativa, exceto na borda em escova. No coelho houve reação positiva para glicoproteínas ácidas não sulfatadas e em menor intensidade para glicoproteínas ácidas sulfatadas tanto no extremo apical do epitélio glandular quanto no interior das glândulas. A positividade das glicoproteínas ácidas foi maior na parte cranial, destacando-se que a reação não era homogênea em todo o epitélio glandular, existindo, portanto, zonas negativas (Del Sol \& Vásquez 2002). Na cobaia, a região apical das células dos ductos excretores apresentou positividade para glicogênio, mucina neutra e ácida, sulfatados e não sulfatados (Vásquez \& Del Sol 2010). Na paca, a reação para glicoproteínas ácidas sulfatadas foi negativa em todas as regiões da glândula. No conjugado $\mathrm{PAS}+\mathrm{AB}$ o epitélio apresentou resultado positivo fraco, indicando que estas células possuem afinidade pelo complexo formado por estes corantes. Na reação PAS + Amilase todas as camadas apresentam resultado positivo fraco, sendo mais evidente nas bordas em escova do epitélio e fraca nas outras camadas, ou seja, nas regiões mais coradas por esta reação há presença de carboidratos, mas não de glicogênio.

Estudos histoquímicos mostraram que a próstata do ferret (Mustela putorius furo) contém uma grande quantidade de mucina-sialidase-lábil, assim como fosfatases ácidas e pequenas quantidades de fosfatase alcalina e proteínas (Jacob \& Poddar 1986). Chow et al. (1993) observaram que no hamster (Mesocricetus auratus) o complexo prostático secreta substância rica em zinco (principalmente a glândula coaguladora). Em cobaia, a reação ao PAS foi negativa para as células e secreções da próstata, porém positiva nos ductos excretores (Vásquez \& Del Sol 2010). As células da zona periférica da próstata de viscacha foi fracamente positiva para P.A.S e negativa para as células da zona central. A secreção de ambas as regiões foi positiva para PAS e negativa para AB (Chaves et al. 2010). Na paca, a reação ao PAS foi positivo fraco no tecido conjuntivo e na borda em escova das células epiteliais, enquanto na reação PAS+ amilase o epitélio reagiu fortemente, o tecido conjuntivo da cápsula e da lâmina própria apresentaram reação positiva de média intensidade e a camada muscular não reagiu, mostrando a presença de pequena quantidade de glicoproteínas ácidas e neutras na glândula, em especial na mucosa (epitélio). Na reação com o $\mathrm{AB}$ a lâmina própria reagiu com fraca intensidade, o que mostra a presença de glicoproteínas ácidas carboxiladas e sulfatadas nessa camada. No conjugado PAS $+\mathrm{AB}$ a borda em escova do epitélio reagiu fracamente, mostrando afinidade pelo complexo formado pelos corantes.

Nas reações histoquímicas, ao PAS, a glândula coaguladora apresentou reação positiva fraca na borda em escova do epitélio e na lâmina própria da mucosa, sendo negativa nas demais camadas, e a reação PAS + amilase o tecido conjuntivo da lâmina própria reagiu fortemente e o epitélio reagiu com menor intensidade, indicando a presença de glicoproteínas neutras nas regiões positivas. Na viscacha, o epitélio da glândula coaguladora foi negativo ao P.A.S, mas a secreção foi fortemente positiva (Chaves et al. 2010). Na coloração A.B. apenas a lâmina própria reagiu, indicando a presença de glicoproteínas ácidas carboxiladas e sulfatadas nesta camada. Na viscacha, no entanto, tanto o epitélio quanto a secreção foram negativas para $\mathrm{AB}$ (Chaves et al. 2010). No conjugado $P A S+A B$ apenas a borda em escova do epitélio reagiu, mostrando maior afinidade pelo complexo formado por estes corantes.

\section{CONCLUSÃO}

As glândulas anexas do trato reprodutor da paca apresentam características histoquímicas que compartilham certa similaridade com outras espécies da Ordem Rodentia, com a presença de glicoproteinas neutras e ácidas em algumas glândulas, principalmente no epitélio da glândula bulbouretal e na borda em escova do epitélio das demais glandulas.

\section{REFERÊNCIAS}

Behmer O.A., Tolosa E.M.C. \& Freitas Neto A.G. 1976. Manual de técnicas para histologia normal e patológica. Editora da Universidade de São Paulo, São Paulo. 241p.

Borges E.M., Branco E., De Lima A.R., Leal L.M., Martins L.L., Reis A.C., Cruz C., Machado M.R. \& Miglino M.A. 2014 Morphology of accessory genital glands of spotted paca (Agouti paca Linnaeus, 1766). Anim. Reprod. Sci. 145:75-80.

Chaves E.M., Aguilera-Merlo C., Filippa V., Mohamed F., Dominguez S. \& Scardapane L. 2010. Anatomical, histological and immunohistochemical 
study of the reproductive system accessory glands in male Viscacha ( $L a-$ gostomus maximus maximus). Anat. Histol. Embryol. 40:11-20.

Chow P.H., Chan C.W. \& Cheng Y.L. 1993. Contents of fructose, citric acid, acid phosphatase, proteins and electrolytes in secretions of the accessory sex glands of the male golden hamster. Int.J. Androl. 16:41-45.

Cooper G. \& Schiller A.L. 1975. Anatomy of the Guinea Pig. Harvard University Press, Cambridge. 432p.

Del Sol M. \& Vázquez B. 2002. Complejo prostático en el conejo (Oryctolagus cuniculus) Revta Chil. Anat. 20:175-180.

Hafez B. \& Hafez E.S.E. 2004. Reprodução Animal. 7̣a ed. Manole, São Paulo. 513 p.

Jacob S. \& Poddar S. 1986. Morphology and histochemistry of the ferret prostate. Acta Anat., Basel, 125:268-273.

Leal L.M., Freitas H.M., Sasahara T.H.C. \& Machado M.R.F. 2014. The hindlimb arterial vessels in lowland paca (Cuniculus paca Linnaeus, 1766). Anat. Histol. Embryol. DOI: 10.1111/ahe.12160

Menezes D.J.A., Assis Neto A.C., Oliveira M.F. \& Farias E.C. 2010. Morpholo- gy of the male agouti accessory genital glands (Dasyprocta prymnolopha Wagler, 1831). Pesq. Vet. Bras. 30:793-797.

Mollineau W.M., Adogwa A.O. \& Garcia G.W. 2009. The gross and micro anatomy of the accessory sex glands of the male agouti (Dasyprocta leporina). Anat. Histol. Embryol. 38:204-207.

Rodrigues M.N., Oliveira G.B., Albuquerque J.F.B., Menezes D.J.A., Assis-Neto A.C., Miglino M.A. \& Oliveira M.F. 2013. Aspectos anatômicos do aparelho genital masculino de preás adultos (Galea spixii Wagler, 1831). Revta Biotemas 26:181-188.

Tolosa E.M.C., Rodrigues C.J., Behmer A.O. \& Freitas-Neto A.G. 2003. Manual de Técnicas para Histologia Normal e Patológica. Manole, São Paulo. $37 \mathrm{p}$.

Toma J. \& Buzzell G. 1988. Fine structure of the ventral and dorsal lobes of the prostate in the young adult Syrian hamster Mesocricetus auratus. Am. J. Anat. 181:132-140.

Vásquez B. \& Del Sol M. 2010. Estudio morfológico de la próstata y glándulas vesiculares de Cobayo (Cavia porcellus). Int. J. Morphol. 28:13011307. 